\title{
Blood flow indices in single and multiple bearing does
}

\author{
M.A. Abdel-Ghani ${ }^{1,3}$, T.M. El-Sherry ${ }^{1}$, M. Hayder $^{2}$ \\ ${ }^{1}$ Department of Theriogenology, Faculty of Veterinary Medicine, Assuit University, Assuit, Egypt. \\ ${ }^{2}$ Animal Production Research Institute, Agriculture Research Center, Dokki, Giza, Egypt.
}

\begin{abstract}
The aim of present study was to examine the changes in blood flow indices throughout pregnancy in singleton and multiple pregnant does. Doppler scanning was done to assess resistance index (RI), pulsatility index (PI), time-averaged maximum velocity (TAMV) and blood flow volume ( $\mathrm{Vol})$. The placentomes were investigated for blood indices on day 45 as an echogenic structure on the surface of the endometrium. Transrectal ultrasonography was performed every 30 days during the overage of the pregnancy. Diameters of largest six placentomes from each doe were measured using an ultrasonography device, and the mean values of placentome diameters were calculated. Values of RI and PI exhibited a steady decrease toward term and declined more rapidly and earlier in multiple than in single pregnancies. Values of RI and PI were negatively correlated with placetome size; however, values of TAMV and Vol were positively correlated with placentome size. In singleton and multiple pregnancies, the placentome size showed an increase toward term, but there is no difference in placentome size between single and multiple bearing does. In conclusion, the values of TAMV and Vol for multiple pregnancies were significantly higher than for singleton at any gestational month to satisfy the high foetal demand of nutrients and dissolved oxygen for foetal progression. Knowing the relationship between the foetal number and blood flow parameters could be used in the clinical management of such pregnancies and the early detection or prediction adverse pregnancy outcome.
\end{abstract}

Keywords: blood flow, doppler velocimetry, goats, placentome, pregnancy.

\section{Introduction}

Physiological changes during pregnancy start soon after implantation, involving a sequence of angiogenic events and adaptation of both placental and maternal vascular dynamics (Kingdom et al., 2000). These functional and structural changes in the uteroplacental vascular system with accompanying foetal growth contribute to increasing the blood flow in the low impedance uteroplacental circulation. As the fetal requirements increase, the utero-placental vascular unit remodels to these hemodynamic changes to ensure an adequate blood supply to the developing placenta (Ferrel et al., 1991). Failure in these physiological adaptations is thought to be responsible for the development of adverse outcomes (Ventura et al., 2012).

Uterine blood flow Doppler ultrasound has been extensively studied as a method for indirectly assessing uteroplacental circulation, and has become clinically used as a screening test for early identification of placental damage in pregnancies at risk for severe intrauterine fetal and placental growth restriction (Ventura et al., 2012).

In veterinary medicine, there is available data about the changes of the uterine blood flow in domestic animals including cows (Panarace et al., 2006), mare (Bollwein et al., 2004), bitch (Miranda and Domingues, 2010), queen (Pereira et al., 2012) and buffaloes (Varughese et al., 2013). To the best of our knowledge, there is no reference data to assess placentome blood flow indices in singleton and multiple pregnancies in does. In view of these considerations, the aim of the current study was to investigate changes in the blood flow indices at various months of pregnancy in single and multiple bearing goats.

\section{Materials and Methods}

\section{Animals}

Adult female goats $(\mathrm{n}=40)$ with almost similar age (1.5-3 years) and weight (20-23 kg) were selected from the lot kept at Mallawi Animal Production Research Station, El-Minia, Egypt- (latitude $28^{\circ} 07^{\prime} \mathrm{N}$ and $30^{\circ} 33^{\prime} \mathrm{E}$ ) during Autumn. Sa'idi goats are a local Egyptian breed found in the southern of the country. The animals are kept mainly for meat production. The goats are maintained grazing in pens the entire day. Water and mineral supplement were available $a d$ libitum. Management of the goats did not change throughout the experimental period. Estrous in goats was synchronized using an intravaginal Progestagen impregnated sponge (40 $\mathrm{mg}$ fluorogestone acetate, GFA, Chronogest $\AA$, Intervet, International, boxmeer, Netherland) for 5 days, and they were injected with 2.5 mg of Dinoprost (Lutalyse, Pfizer manufacturing, Purts, Belgium) at the time of sponge insertion. At the time of sponge removal, $10.5 \mu \mathrm{g}$ busereline acetate $(\mathrm{GnRH}$, Receptal, Intervet) was injected i.m. Goats were considered in estrus only if they stood while being mounted by the bucks. Bucks were introduced in the herd during the experiment for breeding purpose. Mating was scheduled every $4 \mathrm{~h}$ until does refuse to be mounted by bucks. The mated goats were recorded and kept under close observation until parturition.

\section{Pregnancy diagnosis and color Doppler scanning}

Ultrasound scanning was performed by the same operator between 08:00 AM and 01:00 PM using a

${ }^{3}$ Corresponding author: mohammed_ali76@hotmail.com 
Doppler ultrasound scanner (Mylab30, Piemedical, Netherlands), equipped with a 6-8 $\mathrm{MHz}$ endorectal linear probe (Lv513). On day 25 after insemination, does were checked for pregnancy using the B-mode transrectal ultrasonography method.

Does was restrained in a standing position and the abdominal wall was compressed to facilitate visualization of the uterus. Rectum was lubricated using hydrosoluble contact gel prior to the insertion of the transducer. The probe was positioned perpendicularly to the abdominal wall and the bladder was identified to orientate the visualization of uterine horns. The transducer was rotated $90^{\circ}$ clockwise and $180^{\circ}$ counterclockwise in order to orient and image the entire reproductive tract.

A total of 33 does were pregnant. The number of single bearing pregnancies was 14 , while the number of multiple bearing pregnancies (i.e. carrying more than one fetus) was 19. Placentomes were easily investigated for blood indices on day 45 as an echogenic structure on the surface of the endometrium. Then, transrectal ultrasonography was performed every 30 days during the overage of the pregnancy. Diameter sizes of the six largest placentomes (these have a cup- like shape) from each doe were measured using ultrasonography device, and the mean values of placentome diameters were calculated.

Doppler measurements were performed at the beginning of the ultrasound examination to determine the blood flow. The parameters that the device displayed for each waveform by applying the automatic mode were resistance index (RI), pulsatility index (PI), peak systolic velocity (S or $\mathrm{Vp}$ ) and end diastolic velocity ( $\mathrm{D}$ or $\mathrm{Vm}$ ). An average of two-three successive waves was required to develop measurements during one cardiac cycle in the automatic mode (Fig. 1 and 2). Placentome PI and blood flow velocity were measured with a Doppler beam angle $<30^{\circ}$. Averages of all the above parameters were calculated for each month of pregnancy. Time-averaged maximum velocity (TAMV) in $\mathrm{cm} / \mathrm{s}$ was calculated from PI, S and D using the equation of Ginther and Utt (2004):

$$
\mathrm{TAMV}=\frac{S-D}{P I}
$$

Blood flow volume (Vol) in $\mathrm{ml} / \mathrm{min}$ was calculated using the equation of Bollwein et al. (2002):

$$
\mathrm{Vol}=\mathrm{TAMV} \times \pi \times\left(\mathrm{D} \times \frac{0.1}{2}\right)^{2} \times 60
$$

All experiments were carried out in accordance with the guidelines for the care and use of the animals approved by the Veterinary Teaching Hospital's Animal Care Committee, Assuit University.
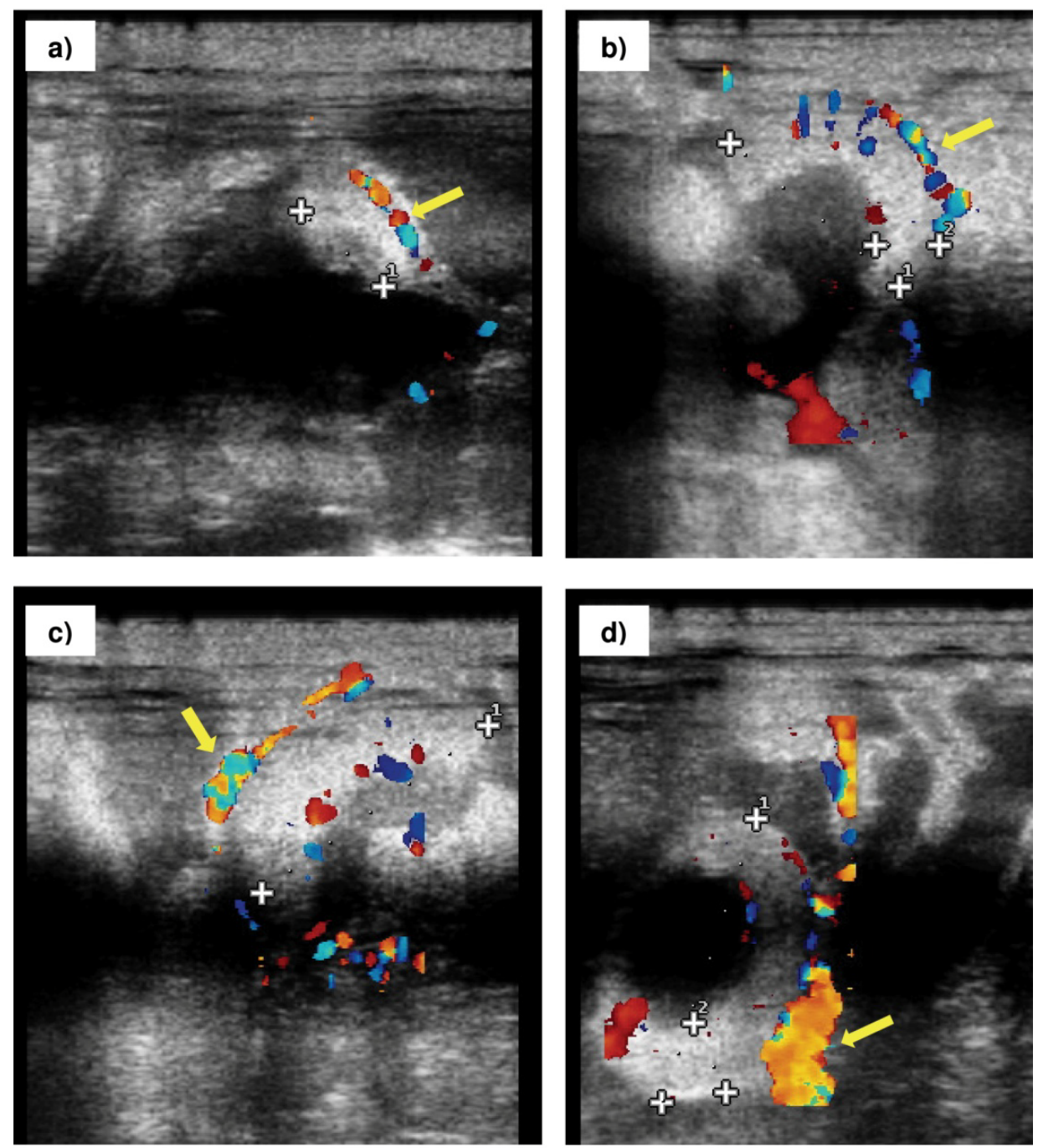

Figure 1. Color Doppler of goat placentome at; (a) second month pregnancy, (b) third month pregnancy, (c) fourth month pregnancy, and (d) fifth month pregnancy showing a detectable blood flow that is thick and surrounded with active blood flow. Colored spots are color Doppler aggregates of pixels of blood flow signals; blue and red indicate blood flow in opposite directions. Note that a gradual increase in the blood flow area and intensity of color (velocity) associated with the increase in the placentome diameter (yellow arrow). 


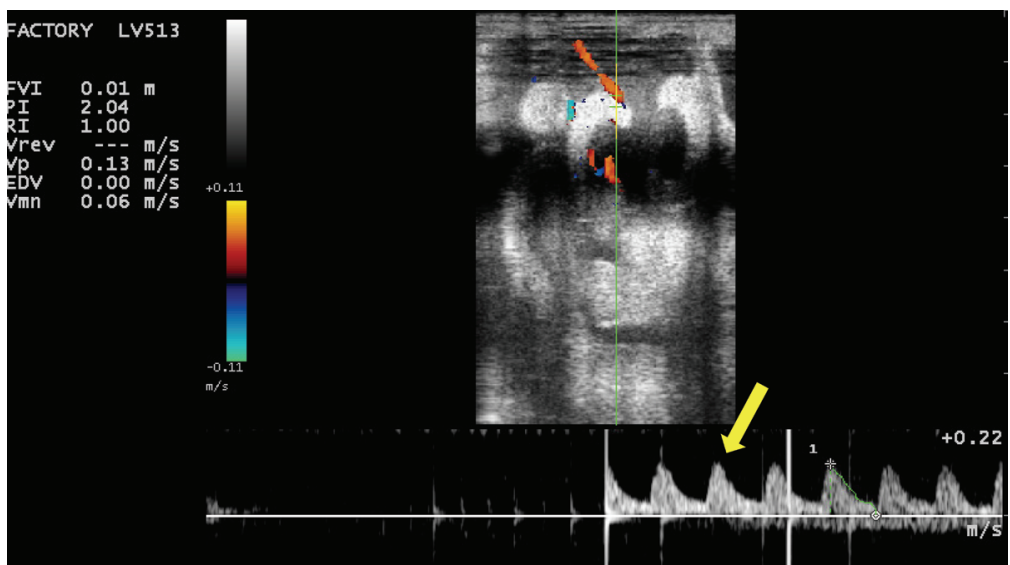

Figure 2. Doppler waveform of blood flow in the goat placentome. Note that after detection of blood flow and visualization of the waveform of the placentome arteries, four blood flow indices were automatically calcualted: pulsatility index (PI), resistance index (RI), peak systolic velocity (S or $\mathrm{Vp}$ ) and end diastolic velocity ( $\mathrm{D}$ or $\mathrm{Vm}$ ). An average of two-three successive waves (yellow arrow) was required to develop measurements during one cardiac cycle in the automatic mode.

Statistical analysis

All data were expressed as mean $\pm \mathrm{SD}$. The PI, RI, TAMV and VOL were analyzed by repeated measure ANOVA to determine main effect of group or group by day. When main effect of group or group by day was observed, the difference of group means at specific time points were analyzed by the student's t-test using JMP statistical software (version 5.1; SAS institute, Cary, NC, USA). The different means were significant at $\mathrm{P}<0.05$ and $\mathrm{P}<0.01$. To analyze the relation between the different parameters, a linear regression relationship was used. Differences of $\mathrm{P}<0.05$ or $\mathrm{P}<0.01$ were regarded as significant.

\section{Results}

The analysis of RI and PI values from 2 to 5 months revealed an effect of group and group by time (P $<0.01$; Fig. 3). Values of RI and PI decreased throughout gestation in single and multiple bearing does. Compared with values in multiple pregnancies, the mean RI and PI values, except for second month, were consistently lower in singletons $(\mathrm{P}<0.05)$.

a)

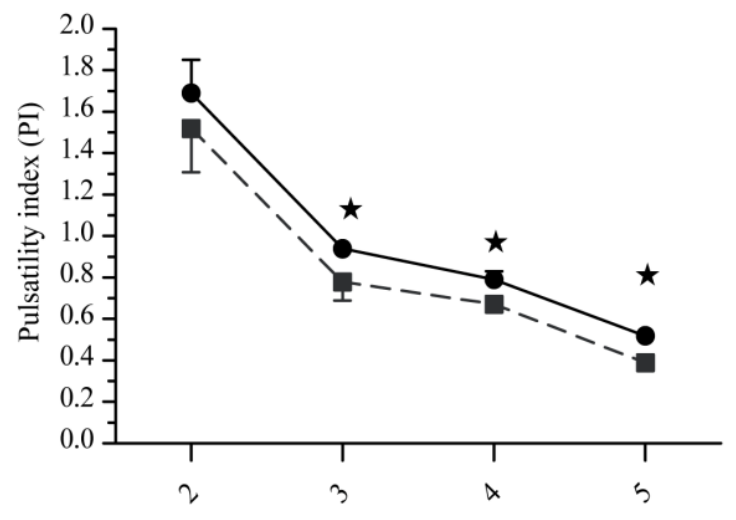

Gestation age (months)

b)

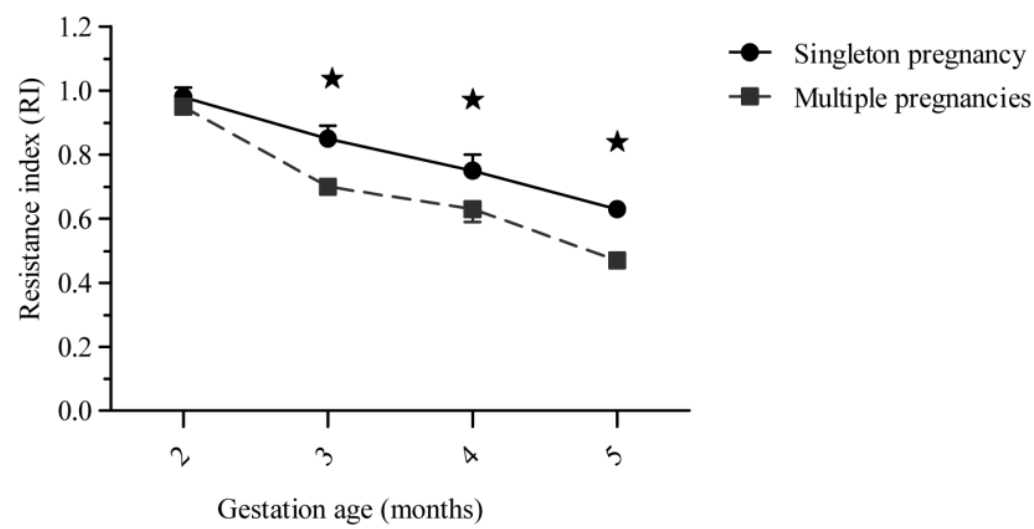

Figure 3. Comparison (mean $\pm \mathrm{SD}$ ) of resistance index $(\mathrm{RI} ; \mathrm{A})$, pulsatility index $(\mathrm{PI} ; \mathrm{B})$ and gestational age in single and multiple bearing goats. Differences $(\mathrm{P}<0.05)$ between the two groups were denoted by $\star$. 
Analysis of TAMV and Vol from 2 to 5 months revealed an effect of group and group by time (P $<0.01$; Fig. 4). Values of TAMV and Vol increased over the course of pregnancy. Values of TAMV and Vol in placentome of multiple pregnancies were consistently higher than that of singleton at any gestational month ( $\mathrm{P}<0.05$; Fig. 4). Values of TAMV increased to 1.3 ,
1.5 and 2 folds the original values in singleton pregnancies, and increased to $1.4,1.4$ and 2 folds in multiple. Values of $\mathrm{Vol}$ increased from the original values in singleton pregnancies to $1.6,2$ and 3 , but in multiple pregnancies they increased to $1.8,2$ and 3.4 , with differences between singleton and multiple pregnancies in the rate of increase $(\mathrm{P}<0.05)$.

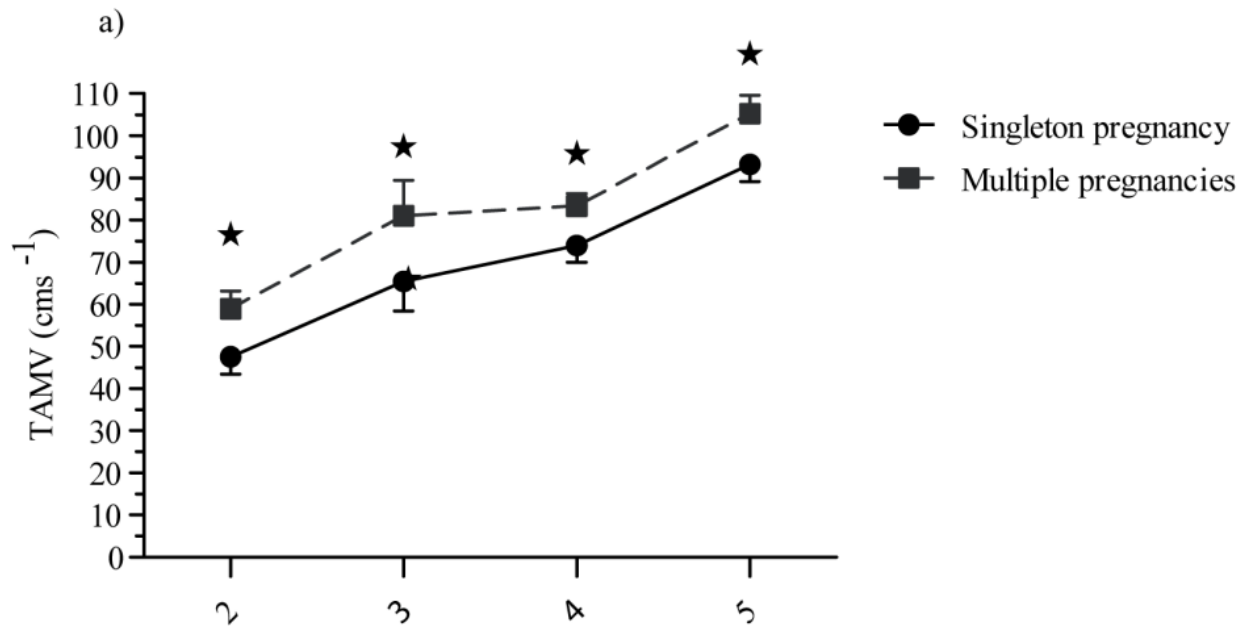

Gestation age (months)

b)

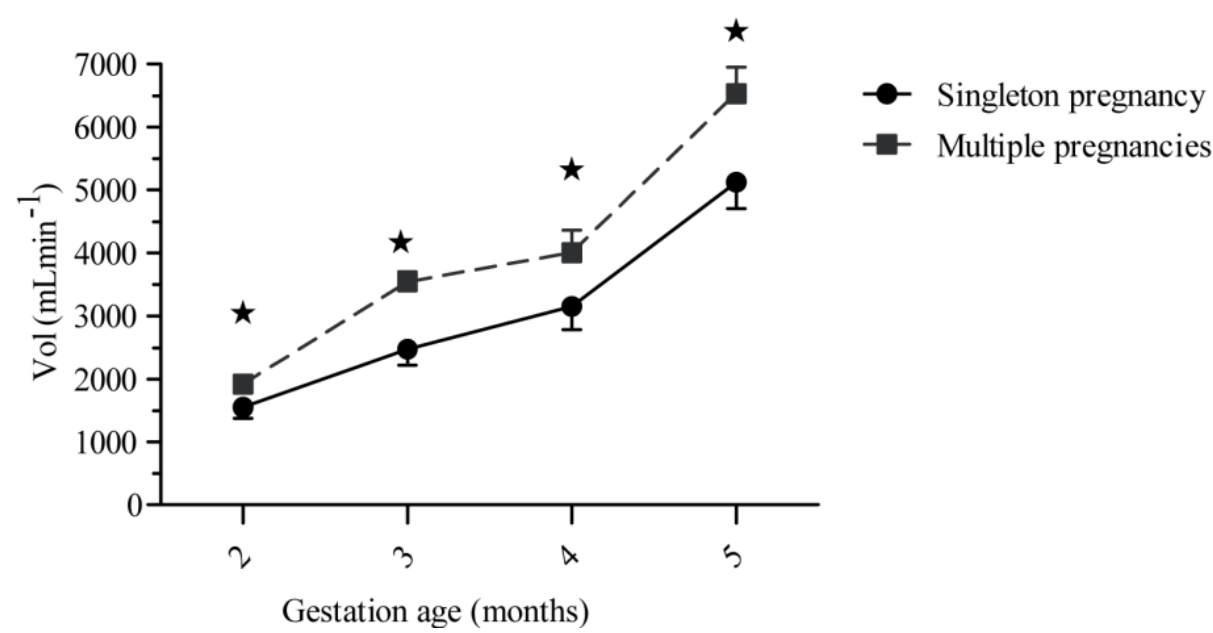

Figure 4. Comparison (mean $\pm \mathrm{SD}$ ) of the time-averaged maximum velocity (TAMV), the blood flow volume (Vol) and gestational age in single and multiple bearing goats. Differences $(\mathrm{P}<0.05)$ between the two groups were denoted by $\star$

In singletons, RI and PI values were negatively correlated with placetome size $\left(r^{2}=-0.78, \mathrm{P}<0.0001\right.$; $r^{2}=-0.89, \mathrm{P}<0.0001$, respectively). Values of TAMV and $\mathrm{Vol}$ were positively correlated with placentome size $\left(r^{2}=0.93, \mathrm{P}<0.0001 ; r^{2}=0.91, \mathrm{P}<0.0001\right.$ respectively). Similarly, in multiple pregnancies, RI and PI were negatively correlated with placetome size (RI versus placentome size, $r^{2}=-0.97, \mathrm{P}<0.0001$; PI versus placentome size, $\left.r^{2}=-0.90, \mathrm{P}<0.0001\right)$. Values of TAMV and Vol were positively correlated with placentome size (TAMV versus placentome size, $r^{2}=$ $0.89, \mathrm{P}<0.0001$; Vol versus placentome size, $r^{2}=0.79$, $\mathrm{P}<0.0001)$.

In singleton and multiple pregnancies, the placentome size showed a steady increase toward the term. However, there is no difference in placentome size between single and multiple bearing does $(\mathrm{P}>0.05$; Fig. 5). 

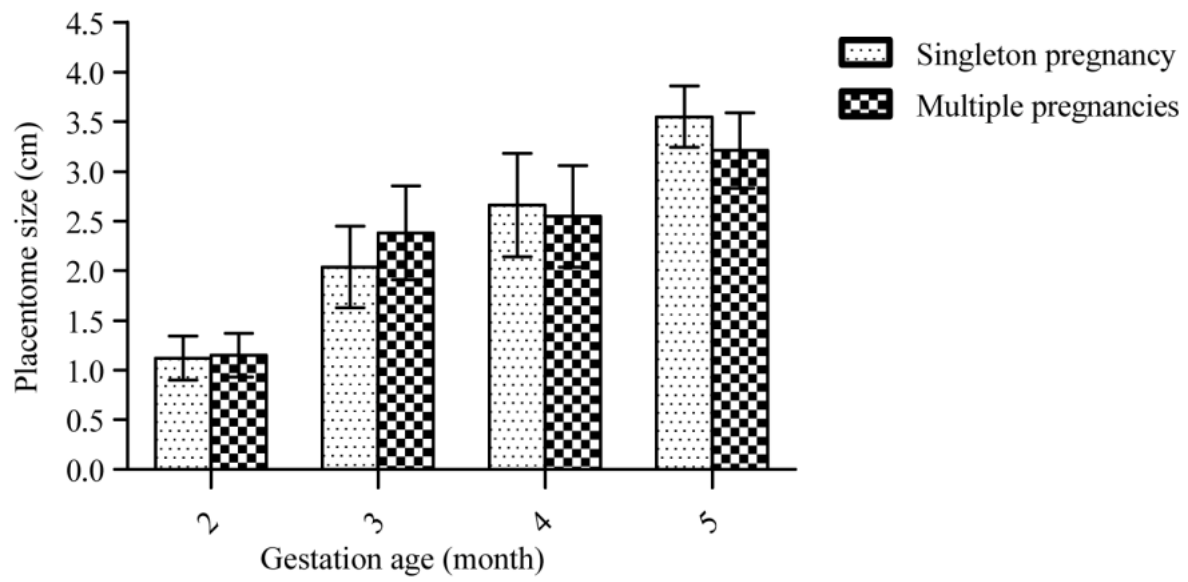

Figure 5. Comparison (mean $\pm \mathrm{SD}$ ) of placentome size and gestational age in single and multiple bearing goats. There is no difference between placentome sizes in singleton and multiple pregnancies $(\mathrm{P}>0.05)$.

\section{Discussion}

As well as cardiovascular changes that take place throughout pregnancy, regional blood flow changes occur in the normal adaptation to pregnancy, and there is a dynamic distribution of blood flow into the uterus. This physiological adaptation is thought to have a particular role in special circumstances, such as adaptation to multiple bearing uteri.

In the current study, as pregnancy progressed, there was a significant negative correlation and distinct reductions in RI and PI of placentome with increases in placentome size. The mean value of RI reflects the resistance to blood flow caused by the microvascular bed, a higher resistance indicated that the force of the blood against the artery walls is high, resulting in lower blood perfusion to the particular organ (Ginther and Utt, 2004). Besides, a high PI indicated decreased perfusion to distal tissues (Ginther and Utt, 2004). Therefore, this reduction is essential for continuous maternal blood flow through the placenta and for constant supply of oxygen and nutrients (Jaffe, 1995). In addition, in response to increasing demands for nutrients, the growth marking of placentomes was related by a direct route to the development of new vessels and to increases in the diameter of the circulatory channels (Meschia, 1983). The reason for the observed alterations in placentome blood flow could be a result from the alteration in the middle uterine artery vasculature. Varughese et al. (2013) assessed and quantified the blood flow parameters at various stages of pregnancy in dairy buffaloes, and reported that RI and PI values of the middle uterine artery ipsilateral and contralateral to the foetus decreased, suggestive of greater perfusion to the gravid horn with least resistance.

Blood flow is the continuous circulation of blood in the cardiovascular system. This process ensures the transportation of nutrients, hormones, metabolic wastes, $\mathrm{O}_{2}$ and $\mathrm{CO}_{2}$ to maintain cell-level metabolism (Tortora and Derrickson, 2012). Mean values of TAMV and Vol increased throughout gestation. The changes in the TAMV and Vol were significantly greater in multiple pregnancies versus singleton; and these were clear indications of arterial response to the increasing demand of growing fetus in multiple bearing goats.

In singleton and multiple pregnancies, the placentome size exhibited a steady increase toward term. Therefore, placentome diameter may be a good measurement to describe the development of the placenta during pregnancy and the relationship between foetal development and placental growth. However, Doize et al. (1997) demonstrated that, in ewes, there was a poor correlation of placentome size with gestational age. Kaulfuss et al. (1998) reported that placentome diameter increased more in twin bearing ewe than in singleton during the third month of pregnancy. Similarly, Kaşikç et al. (2011) showed that there was no significant difference in placentome diameter size in single and twin-pregnant ewes except during the 5 and 12th weeks. Contrary to this, in the present study, there is no difference in placentome size between single and multiple pregnant goats. Nutritional and blood demands by two fetuses were higher than one fetus, while placentome size was similar in both pregnancies, which was compensated by increased placentome vascularization and permeability of blood vessels to allow a greater supply of nutrients, hormones, growth factors, and dissolved oxygen, which are important for the growth of two foetuses, resulting in foetal progression. Thus, this may explain why the values of TAMV and Vol of placentome of multiple pregnancies were significantly higher than that of singleton throughout pregnancy, and why there were greater reductions in RI and PI in the multiple compared to single bearing goats to maintain a normal uteroplacental blood flow. Similarly, Rigano et al. (2007) have documented that in human twin pregnancies impedance to flow in the uterine arteries is lower than in singleton pregnancies and uterine artery flow volume was significantly increased, which was determined by larger vessel diameter, compared to singletons.

In conclusion, values of TAMV and Vol of multiple pregnancies were significantly higher than that of singleton at any gestational month to satisfy the high foetal demand of nutrients and dissolved oxygen for foetal progression. Furthermore, understanding the relationship between foetal number on one side and 
blood flow parameters on the other side could be useful in the clinical management of such pregnancies.

\section{Acknowledgment}

This study was kindly supported by the project of Introducing Improved Genotypes and better management to increase small ruminant roles in conventional Egyptian farming as an investment or income pattern. Grant No: $416 \mathrm{~B}$.

\section{References}

Bollwein H, Baumgartner U, Stolla R. 2002. Transrectal Doppler sonography of uterine blood flow in cows during pregnancy. Theriogenology, 57:20532061.

Bollwein H, Weber F, Woschée I, Stolla R. 2004. Transrectal Doppler sonography of uterine and umbilical blood flow during pregnancy in mares. Theriogenology, 61:499-509.

Doize C, Vaillancourt D, Carabinf H, Belange D. 1997. Determination of gestational age in sheep and goats using transrectal ultrasonggraphic measurement of placentomes. Theriogenology, 48:449-460.

Ferrel CL. 1991. Maternal and fetal influences on uterine and conceptus development in the cow II. Blood flow and nutrient flux. J Anim Sci, 69:1954-1965.

Ginther OJ, Utt MD. 2004. Doppler ultrasound in equine reproduction. Principles, techniques and potential. J Equine Vet Sci, 24:516-526.

Jaffe R. 1995. Colour Doppler imaging in the evaluation of normal and abnormal early uteroplacental circulation and gestational outcomes. Theriogenology, 43:121-127.

Kaşikçi G, Yilmaz ÖT, Gündüz MC, Kirşan I. 2011. Comparison of placentome diameters in single and twin-pregnant sheep by ultrasonographic method. Turk J Vet Anim Sci, 35:187-191.

Kaulfuss KH, Uhlich K, Gille U. 1998. Ultrasonographic examination of the placentome development in pregnant sheep. Dtsch Tierarztl
Wochenschr, 105:162-167.

Kingdom J, Huppertz B, Seaward G, Kaufmann P. 2000. Development of the placental villous tree and its consequences for fetal growth. Eur J Obstet Gynecol Reprod Biol, 92:35-43.

Meschia G. 1983. Circulation to female reproductive organs. In: Schepherd JT, Abbound FM (Ed.). Handbook of Physiology. Bethesda, MD: American Physiological Society. Sect 2, vol III. pp. 241-269.

Miranda SA, Domingues SFS. 2010. Conceptus ecobiometry and triplex Doppler ultrasonography of uterine and umbilical arteries for assessment of fetal viability in dogs. Theriogenology, 74:608-617.

Panarace M, Garnil C, Marfil M, Jauregui G, Lagioia J, Luther E, Medina M. 2006. Transrectal Doppler sonography for evaluation of uterine blood flow throughout pregnancy in 13 cows. Theriogenology, 66:2113-2119.

Pereira BS, Pinto JN, Freire LMP, Campello CC, Domingues SFS, da Silva LDM. 2012. Study of the development of uteroplacental and fetal feline circulation by triplex Doppler. Theriogenology, 77:989997.

Rigano S, Boito S, Maspero E, Mandia L, Padoan A, Pardi G, Ferrazzi E. 2007. Absolute uterine artery blood flow volume is increased in twin human pregnancies compared to singletons. Ultrasound Obstet Gynecol, 30:456-546.

Tortora GJ, Derrickson BH. 2012. The cardiovascular system. The blood. In: Tortora GJ, Derrickson BH. Principles of Anatomy \& Physiology. 13th. New York, NY: John Wiley. pp. 729-732.

Varughesea EE, Brara PS, Dhindsab SS. 2013. Uterine blood flow during various stages of pregnancy in dairy buffaloes using transrectal Doppler ultrasonography. Anim Reprod Sci, 140:34-39.

Ventura W, De Paco C, Delgado JL, Blanco JE, Peñalver C, Parrilla JJ. 2012: Reliability of examining the external iliac artery with Doppler ultrasound in the first trimester and its relationship with maternal blood pressure and uterine artery blood flow. Eur J Obstet Gynecol Reprod Biol, 165:42-46. 